\title{
EVALUATING THE "ANALYSIS AND PROBLEM SOLVING” COMPETENCE AT MASTER CONTEXT WITH A WEIGHTED APPROACH
}

\author{
Raúl Rodríguez-Rodríguez, María-José Verdecho, Pedro Gómez-Gasquet, Juan- \\ José Alfaro-Saiz \\ Department of Business Organization, Universitat Politècnica de València (SPAIN)
}

\begin{abstract}
This paper presents the main results of measuring whether and to what extent the transversal competency called "Analysis and problem solving" has been achieved in a High Education Master Degree course. This course was, more concretively, the named "Management of Performance Management" and counted with 27 students, being taught at the Polytechnic University of Valencia in Valencia, Spain. Such an university has encouraged in the last years the development of different innovative educational projects in order to improve the quality of its teaching. Additionally, these educational projects focus on specific transversal competencies to be improved. The evaluation of the acquisition of the competence under study in this paper was made under a group approach. In order to evaluate the acquisition of such a competence from the different groups formed, some performance indicators, grouped into attributes of performance, were applied. Since not all of these indicators had the same importance when evaluating the acquisition of the competence, a weighted approach was used. This performance tool, formed by performance attributes and performance indicators, was applied in different moments during the course in order to better evaluate the achievement of the competence.
\end{abstract}

Keywords: Transversal competences; evaluation; performance tool; analysis and problem solving.

\section{TRANSVERSAL COMPETENCES AT THE POLYTECHNIC UNIVERSITY OF VALENCIA}

The Polytechnic University of Valencia (UPV) counts with about 30.000 students and 6.000 staff people, including in the latter some 2.500 lecturers of different levels. It created a specific centre to manage educative tasks for this staff: The Education Science Institute (ICE). It is this entity the one that has put more emphasis on the students to develop different competencies in the past 20 years. With the arrival of Bologna and its educational competencies approach, the ICE has defined different competencies skills, generic and transversal ones, to be achieved by students. Focusing on the transversal competencies to be acquired, the ICE defined the next main thirteen ones:

Table 1- Main transversal competencies.

\begin{tabular}{|l|l|}
\hline TC-1 Understanding and integration & TC-8 Effective communication \\
\hline TC-2 Application practical thinking & TC-9 Critical thinking \\
\hline TC-3 Analysis and problem solving & TC-10 Knowledge of contemporary issues \\
\hline TC-4 Innovation, creativity and entrepreneurship & TC-11 Continuous learning \\
\hline TC-5 Project design & TC-12 Planning and time management \\
\hline TC-6 Teamwork and leadership & TC-13 Instrumental specific \\
\hline TC-7 Professional and ethical responsibility & \\
\hline
\end{tabular}

Depending on the specific subject/course taught the importance of reaching one or another will change, thought the acquisition of all of them is desired. In any case, along with the need of implementing and achieving these competences by students come up the need of controlling and monitoring to what extent these have been achieved. In other words, some kind of performance measurement system/assessment tool was needed. The ICE provided general guidelines to define 
rubrics in order to measure the achievement of transversal competencies; however, it has been detected that the personalisation of the developed rubrics to the specific course that they are applied to it would benefit to the own measurement process and obtained results. The idea is to define weights for different attributes defined within a rubric established at the PIME project in order to better measure transversal competencies. The PIME project is a teaching innovation project formed by 8 teachers from the UPV and promoted by the ICE, whose main aim is to allow teachers to develop common tools and mechanisms for improving the teaching quality level.

This paper focuses on presenting a weighted approach tool for measuring how a specific competence has been achieved in a course called "Management of Performance Management", which counted with 27 students and was taught within the Master of Advanced Engineering Production, Logistics and Supply Chain (MUIAPLCS). The MUIAPLCS is an official UPV postgraduate (Master) degree, which is inside the Industrial Production Engineering doctorate programme. The MUIAPLCS is a one-year programme, where the students must successfully overcome 60 ECTS credits and develop a final master thesis.

Then, this paper is structured as follows: in the next point presents a brief introduction to the evaluation of competences in groups; then, the weighted assessment tool (rubric) is presented; then, the main results of applying such a weighted rubric are developed; finally, the main conclusions are presented.

\section{EVALUATING COMPETENCIES IN GROUPS}

When evaluating any learning process it is important to bear in mind what it is learnt, how it is learnt and under what circumstances is learnt [1]. Then, within the current EEES there are different key points that should direct to docents to potentiate certain skills and abilities from the students. In this context, it is of high relevance to accomplish that students, when working in a group, are motivated and participate as ECUANIME as possible in the activities to be performed.

However, evaluation of group activities is not easy, and it has been determined that, probably, the best way of evaluating the performance of a group is to provide a global mark for the group and then the own members of the group determine the final mark for each individual [2], [3].

Even thought the MUIAPLCS incorporated its own tools, both qualitative and quantitative, to measure general and specific competencies, there was still a need to create a tool that would be the same one to measure the same competency and therefore a basis to compare would be available too.

Considering these points, the group of teachers forming the PIME project designed a scoring rubric adapted to measuring the Analysis and Problem Solving transversal competence. The lack of previous culture on transversal competence analysis represented the major issue when creating a tool that simultaneously helps to describe the concept itself and to provide a score to students.

The next point presents the developed rubric; its main structure and the weighted approach designed in order to better evaluate the achievement of the transversal competency.

\section{WEIGHTED ASSESSMENT TOOL}

The use of scoring rubrics as a measurement method has different inherent considerations [4]. In order to design a rubric for a transversal competence, the members of the ICE project considered that the rubric should:

- Be applicable in a context of either high or low number of students.

- Be possible to use in different subjects and programs.

- Avoid ambiguity.

- Help to differentiate the students evaluated at least in 3 groups (Target achieved, on track to meet the target, target not achieved). Introducing least possible error.

- Be a self-assessment tool.

- Chart data easily in a 1-10 scale.

As a result of this work, the proposed rubric developed and its final version is shown in Table 2. 
Table. 2 - Generic rubric.

\begin{tabular}{|c|c|c|c|c|c|}
\hline & & 1 & 2 & 3 & GROUP \\
\hline & $\begin{array}{l}\text { Analyses the causes and effects of problems from a global } \\
\text { long-term approach }\end{array}$ & & & & \\
\hline 1 & Sets the context of the problem & & & & \\
\hline \multirow[t]{2}{*}{2} & $\begin{array}{l}\text { Defines the problem to solve describing clearly and concisely the } \\
\text { facts (data) and most important variables }\end{array}$ & & & & \\
\hline & $\begin{array}{l}\text { Applies advanced search criteria information for } \\
\text { troubleshooting and evaluates the quality of information }\end{array}$ & & & & \\
\hline 3 & Validates the model or contrast the data problem & & & & \\
\hline 4 & Generalizes or extends the problem & & & & \\
\hline \multirow[t]{2}{*}{5} & Analyses valuable literature & & & & \\
\hline & Organized in a systematic way to work decision & & & & \\
\hline 6 & Establishes a scientific system to analyse and propose solutions & & & & \\
\hline \multirow[t]{2}{*}{7} & Learned methods are adapted to the case & & & & \\
\hline & $\begin{array}{l}\text { Evaluates possible solutions as viable scientific and technical } \\
\text { difficulty of implementation }\end{array}$ & & & & \\
\hline 8 & The solution is clearly exposed & & & & \\
\hline 9 & The solution is adapted to be used in a real environment & & & & \\
\hline 10 & Proposes alternative solutions & & & & \\
\hline
\end{tabular}

The rating on the scale is quantitative $(0-10)$, and its equivalent is:

- 10-9: Excellent.

- 8.99-8: Very Good.

- 7.99-6: Good.

- 5.99-5: Pass.

- Under 5: Insufficient.

As it can be seen, four blocks have been established according to the suggestion made by [6] for the assessment of this competence in the level corresponding with postgraduate course. Each of these four blocks contains between 2 and 3 dimensions.

This rubric, as it is above presented, was used in other courses from the MUIAPLCS obtaining good and interesting results. However, it was thought that more could be done to improve such a rubric and then a performance measurement approach was applied. The four blocks could be seen as attributes of performance and the associated dimensions as performance indicators. Since not all of these indicators had the same importance when evaluating the acquisition of the competence, a weighted approach was used. This performance tool, formed by performance attributes and performance indicators, was applied in different moments during the course in order to better evaluate the achievement of the competence.

Then, the following operations were developed:

a) Different weights were allocated to these four performance attributes (summing up to $100 \%$ points the four scores). These weights were decided to be the following ones:

b) Different individual weights were given to the performance indicators (dimensions) within a performance attribute ( $0-10$ scale for each indicator's weight).

The next table illustrates the different weights allocated to both the blocks/attributes and the indicators/dimensions of performance. 
Table 3 - Weighted rubric.

\begin{tabular}{|c|c|c|}
\hline & & GROUP \\
\hline & $\begin{array}{l}\text { Analyses the causes and effects of problems from a global long-term } \\
\text { approach }(10 \%)\end{array}$ & \\
\hline 1 & Sets the context of the problem ( 7$)$ & \\
\hline \multirow[t]{2}{*}{2} & $\begin{array}{l}\text { Defines the problem to solve describing clearly and concisely the facts (data) } \\
\text { and most important variables (9) }\end{array}$ & \\
\hline & $\begin{array}{l}\text { Applies advanced search criteria information for troubleshooting and } \\
\text { evaluates the quality of information }(25 \%)\end{array}$ & \\
\hline 3 & Validates the model or contrast the data problem (7) & \\
\hline 4 & Generalizes or extends the problem (8) & \\
\hline \multirow[t]{2}{*}{5} & Analyses valuable literature (9) & \\
\hline & Organized in a systematic way to work decision $(35 \%)$ & \\
\hline 6 & Establishes a scientific system to analyse and propose solutions (10) & \\
\hline \multirow[t]{2}{*}{7} & Learned methods are adapted to the case (8) & \\
\hline & $\begin{array}{l}\text { Evaluates possible solutions as viable scientific and technical difficulty of } \\
\text { implementation (30\%) }\end{array}$ & \\
\hline 8 & The solution is clearly exposed (9) & \\
\hline 9 & The solution is adapted to be used in a real environment (10) & \\
\hline 10 & Proposes alternative solutions (7) & \\
\hline
\end{tabular}

Then, in order to obtain an attribute/block final score it should be proceed as follows:

- Fill-in the score for each performance indicator/dimension following a 0-10 scale.

- Multiplies the performance indicator score by the individual weight allocated to such indicator.

- Sum all the results of these multiplications, obtaining the global score for a specific performance attribute.

- Multiply the global score by the performance attribute weight and the number of performance indicators/dimensions of the performance attribute divides the result.

Once that this procedure has been followed, a final weighted score of the transversal competence under study is worked out by summing the four final scores calculated with the above procedure. This weighted approach is flexible and allows to easily introducing changes in the weights of both the four performance attributes/blocks and the performance indicators/dimensions. The next point presents the main results obtained of applying this weighted approach to a course of the MUIAPLCS.

\section{ANALYSIS OF RESULTS}

\subsection{Using the weighted rubric}

The use of a rubric will provide the situation of the acquisition of the transversal competency in a certain moment. Therefore, it will be desirable to apply in different moments of the course, providing a basis for comparison and better information. This comparison will be able to be made not only within a group but also between groups of different academic years; additionally, comparisons will also be made between different courses of the MUIAPLCS. Such a inter and intra course measurement will provide data and information that right now is missing in the MUIAPLCS regarding assessment of achievement of transversal competencies.

It is also important to highlight the importance of properly communicate and transmit the essence and structure of the weighted rubric to students; usually, they could see all related with measurement as a 
control tool with possible negative connotations; docents must deliver the appropriate actions to avoid this, as otherwise the final purpose of the assessment process would not be properly reached.

\subsection{Results reached}

The weighed rubric was applied to the course called "Management of Performance Management", which counted with 27 students. It was applied twice to 2 different group activities. The first activity was about defining strategic objectives, derived from a given strategic line, for different supply chains. This activity was orally defended by the different groups. The second activity was conducting a correlation analysis between some KPIs given and posterior analysis of the cause-effect relationships identified. The students summarised their works on an executive Word report.

Table 4 - Mean results achieved with the application of the weighted rubric.

\begin{tabular}{|c|c|c|}
\hline & Activity1 & Activity2 \\
\hline Analyses the causes and effects of problems from a global long-term approach (10\%) & 6,1 & 5,7 \\
\hline Sets the context of the problem (7) & 7,0 & 8,0 \\
\hline $\begin{array}{l}\text { Defines the problem to solve describing clearly and concisely the facts (data) and most important variables } \\
\text { (9) }\end{array}$ & 8,0 & 6,5 \\
\hline $\begin{array}{l}\text { Applies advanced search criteria information for troubleshooting and evaluates the quality of } \\
\text { information (25\%) }\end{array}$ & 13,4 & 15,0 \\
\hline Validates the model or contrast the data problem (7) & 6,0 & 7,0 \\
\hline Generalizes or extends the problem (8) & 7,0 & 8,0 \\
\hline Analyses valuable literature (9) & 7,0 & 7,5 \\
\hline Organized in a systematic way to work decision (35\%) & 23,8 & 24,2 \\
\hline Establishes a scientific system to analyse and propose solutions (10) & 8,0 & 7,0 \\
\hline Learned methods are adapted to the case (8) & 7,0 & 8,5 \\
\hline Evaluates possible solutions as viable scientific and technical difficulty of implementation ( $30 \%)$ & 19,6 & 20,7 \\
\hline The solution is clearly exposed (9) & 7,0 & 7,5 \\
\hline The solution is adapted to be used in a real environment (10) & 7,0 & 8,0 \\
\hline Proposes alternative solutions (7) & 9,0 & 8,5 \\
\hline TOTAL & 62,9 & 65,6 \\
\hline
\end{tabular}

As it can be seen in Table 4, the assessment of the first activity output a total score of 62,9 points whereas the second scored 65,6 points. It can be stated that the students achieved in a higher degree the transversal competency under study in the second activity. This can be due to the own nature of the activity, which was more quantitative than the first one. In any case, this weighted rubric allows partial comparisons between performance attributes; for example, the performance attribute 1 was better achieved in the first activity than in the second one.

\section{ANALYSIS OF RESULTS}

This paper has presented a weighted rubric in order to measure the achievement of a transversal competency called Analysis and Problem Solving in a Master course named "Management of Performance Management", which counted with 27 students.

Such a weighted rubric defined both performance attributes, which were formed with different KPIs/dimensions. This rubric allowed to allocate relative total weights to each one of these performance attributes and also allocate some relative weights to KPIs inside the performance attributes. It is a flexible rubric in the way that weights are easy to be changed for both attributes and KPIs.

This weighted rubric complements the classic approach where usually the same weight was given to all the performance attributes and dimensions. It allows a more detailed comparison when comparing to what extent different activities carried out by the students have lead to the acquisition of the transversal competency.

In future research activities, it should be convenient to apply this weighted rubric to other courses and associated activities in order to have historical data and being therefore able to conduct more analyses. 


\section{ACKNOWLEDGEMENTS}

This work has been developed within the research project called "Assessment of UPV generic competence "problem analysis and resolution" in master students" (Ref.: PIME-A7-15) funded by the Vice-Rectorate for Studies, Quality and Acreditation <https://www.upv.es/entidades/VECA/indexen.html> at Universitat Politècnica de València.

\section{REFERENCES}

[1] Gagné, R. M. (1985). The conditions of learning and theory of instruction. $4^{\text {th }}$ Edition, New York, Rinehart and Winston, 361 páginas.

[2] Sharp, S. (2006). Deriving individual student marks from a tutor's assessment of group work. Assessment \& Evaluation in Higher Education, Vol. 31, Issue 3, pp.329-343.

[3] Morales, P. (2007). Los trabajos en grupo: cómo diferenciar las calificaciones individuales. En Prieto Navarro, Leonor (Coord.). La enseñanza centrada en el aprendizaje: estrategias útiles para el profesorado. Barcelona: Octaedro.

[4] Sonseca, A., Sahuquillo, O., Martinez-Casas, J., Carballerira, F. and Rodenas J.J. (2015). Assessment of oral and written communication competences in the European Higher Education Area: a proposal of evaluation methodologies. Head' $151^{\text {st }}$ International conference on higher education advances. Editorial UPV. 